\title{
Mitochondria-targeted compounds in the treatment of cancer
}

\author{
Minireview
}

\begin{abstract}
A. KAFKOVA, J. TRNKA*
${ }^{1}$ Laboratory for Metabolism and Bioenergetics, Department of Biochemistry, Cell and Molecular Biology and Centre for Research on Nutrition, Metabolism and Diabetes, Third Faculty of Medicine, Charles University, Prague, Czech Republic
\end{abstract}

${ }^{*}$ Correspondence: jan.trnka@lf3.cuni.cz

Received July 25, 2019 / Accepted September 18, 2019

\begin{abstract}
Mitochondria are highly dynamic organelles involved in many cellular functions. Beyond their central role in metabolism, they also take a part in maintaining calcium homeostasis, cell death, immunity, and ROS production. Changes in these functions have been shown to be crucial for the adaptation and survival of cancer cells. Mitochondria, therefore, constitute a promising target for the development of novel anticancer agents. The triphenylphosphonium (TPP ${ }^{+}$moiety has been widely used to target molecules into mitochondria. $\mathrm{TPP}^{+}$derivatives of a variety of conventional cytostatic drugs, natural substances, metformin, antioxidants or a range of newly synthesized molecules have shown promising results against cancer cells. In this review, we discuss biochemical differences between cancer cells and normal cells with a specific focus on mitochondria, and how mitochondrially targeted molecules can be used to selectively affect mitochondrial function in normal and cancer cells. We summarize the published data on mitochondrially targeted anticancer agents and propose future research avenues.
\end{abstract}

Key words: mitochondria, cancer, triphenylphosphonium, targeting, cytotoxic

\section{Role of mitochondria in cancer}

Cancerous tumors represent a collection of cells that have undergone a malignant transformation characterized by altered metabolism, immune evasion, genome instability and mutations, resistance to cell death, uncontrolled growth and proliferation. Since mitochondria are major metabolic organelles, their contribution towards tumor growth, including mitochondrial DNA (mtDNA) mutations, alterations in oxidative phosphorylation (OXPHOS), calcium and iron homeostasis or process of apoptosis, have been investigated in detail.

One of the first findings in this area was that cancer cells tend preferentially to convert pyruvate to lactate even under aerobic conditions, a phenomenon known as the Warburg effect [1-3]. One of its effects is the diffusion of protons thus produced from the proximal tumor microenvironment into neighboring tissues causing acidification and tissue remodeling leading to a local invasion [4]. Another corollary is a symbiosis of two different subpopulations of cancer cells, where the first one produces lactate and the second one uses the lactate as a source of energy (Cori cycle at the cellular level) $[5,6]$. The lactate production is further accentuated under hypoxic conditions in some cancer cells [7]. Even if this results in less efficient metabolism in terms of ATP production, it provides sufficient energy for cell proliferation.

During cell proliferation, there is a large demand for lipids, amino acids, and nucleotides, the building blocks of new cells. Not only ATP is required for the synthesis of these materials but also large amounts of acetyl-coA (a source of carbons) and NADPH (a source of electrons). In fact, if we take the ratio of these products, more equivalents of NADPH and carbons are needed compared to molecules of ATP [3]. Even though it has been believed for decades that the factors mentioned above are the reason for cancer cells disposing of OXPHOS, the Krebs' cycle and the mitochondrial respiratory chain are not always switched off, in fact, their activity depends on the tumor type, stage or size as recently reviewed by Jose et al. [8]. The Krebs' cycle, although often modified or truncated, generates intermediates necessary to synthesize 
metabolites such as lipids or nucleotides $[9,10]$, with glutamine shown to be an important resource [11]. Additionally, specific functions of the electron transport chain such as enabling the biosynthesis of aspartate [12] or the generation of ROS important for modulation of cell cycle progression and proliferation have been reported $[13,14]$. In some tumors, the fate of pyruvate seems to be dependent on other factors, such as the activity of enzyme pyruvate kinase M2, one of the rate-limiting enzymes in glycolysis. The activity of pyruvate kinase M2 has been shown to be regulated via mTOR signaling. mTOR phosphorylates Mfn2, leading to its interaction with pyruvate kinase M2. This mTOR-Mfn2pyruvate dehydrogenase kinase signaling axis couples glycolysis and OXPHOS to modulate cancer cell growth [15].

The role of mtDNA in cancer is less clear, however, recent experiments confirm that mtDNA mutations can impart malignant properties on cells, causing an oncogenic or metastatic metabolic switch. On the other hand, mtDNA mutations resulting in severe mitochondrial dysfunction might have a detrimental effect on the cancer cell [16].

Regulated cell death by apoptosis is an active process, which is critical in preventing tumorigenesis. Indeed, resistance to cell death is a classical hallmark of cancer, whereby cancer cells exhibit suppressed apoptosis thus enabling further transformation, with multiple levels of regulation in place [17]. The Bcl-2 family of proteins, which includes anti-apoptotic, pro-apoptotic and BH3-only members, is the master regulator of this process [18] playing roles in the sensing of cellular stress (i.e. DNA damage [19] or ER stress [20]) as well as in the initiation of apoptosis through regulating mitochondrial integrity in a process known as mitochondrial outer membrane permeabilization (MOMP). This is followed by the activation of executioner caspases finally resulting in a loss of the inner mitochondrial membrane potential and ATP synthesis and an increased level of reactive oxygen species [21]. During tumorigenesis, the apoptotic program can be deregulated at several levels of apoptotic regulation, which can lead to cancer initiation and also drive cancer progression $[22,23]$.

Mitochondrial $\mathrm{Ca}^{2+}$ also plays a crucial role during cancer. It is known to be important in apoptosis [24, 25], regulation of cellular energetics [26], and cell migration $[27,28]$, all of which are disrupted in cancer. Located in the inner mitochondria membrane, the mitochondrial calcium uniporter (MCU) and its regulators are responsible for the main entry of calcium into the matrix [29-32]. Studies searching for potential correlations between the expression of MCU complex components and tumor progression have suggested that the MCU complex and its components have different roles in different cancer types and stages [33, 34]. As calcium plays a role in cell migration, MCU and mitochondrial calcium uptake enhance metastasis $[35,36]$. On the other hand, it has been shown that downregulation of MCU in colon cancer cells and reduced mitochondrial calcium uptake also contributes to resistance to apoptotic signals [34].
Many studies have shown that some of the neoplastic diseases are linked to abnormalities of iron metabolism [37-41]. Mitochondria are one of the key organelles in iron homeostasis [42], therefore, it is not surprising that this presents another possible role in tumorigenesis. Indeed, it has been suggested that mitochondrial iron plays a role in the metabolic programming and inflammation processes in tumor development $[43,44]$.

Changes in the mitochondrial function in cancer cells are summarized in Figure 1.

\section{Targeting mitochondria using triphenylphosphonium}

Triphenylphosphonium $\left(\mathrm{TPP}^{+}\right)$and its preferential accumulation in mitochondria. As mentioned above, mitochondria are functionally versatile structures involved in indispensable activities for cell survival. Therefore, the possibility of manipulating their functions such as OXPHOS, calcium homeostasis or the regulation of apoptosis makes them ideal targets for specific anticancer drug delivery. However, getting drugs into mitochondria is not so straight forward due to the necessity to cross several lipid bilayers and in particular, the inner mitochondrial membrane, which is highly selectively permeable for molecules to enter the matrix [45]. Despite this obstacle, different methods have been developed to target molecules into mitochondria, such as mitochondria targeting peptides [46], mitochondriapenetrating peptides [47], gramicidin S [48] or different lipophilic cations, including rhodamine [49] or triphenylphosphonium and its derivatives $[50,51]$. Out of these targeting molecules, triphenylphosphonium $\left(\mathrm{TPP}^{+}\right)$derivatives have been used perhaps most commonly. One reason for this is because they can be used to deliver different bioactive molecules directly into the mitochondrial matrix, while peptides end up mostly localized to the inner mitochondrial membrane (IMM) [52, 53]. Another reason for its relatively wide use is the comparably easy chemical manipulation in terms of conjugation with bioactive compounds [54]. In this review, we will, therefore, focus mainly on mitochondrial drug targeting based on $\mathrm{TPP}^{+}$derivatives.

Structurally the $\mathrm{TPP}^{+}$moiety is composed of three hydrophobic phenyl groups that surround a positively charged phosphorus atom. There are three main reasons why the conjugation with $\mathrm{TPP}^{+}$benefits mitochondrial drug delivery; a) increased lipophilicity of phenyl groups helps to create a large hydrophobic surface area b) spreading of positive charge across the molecule c) phenyl groups sterically protect the phosphorus atom shielding it from solvation $[50,55]$. These chemical properties in combination with the large mitochondrial membrane potential lead to its accumulation inside mitochondria. In fact, the uptake of TPP cations into mitochondria increases approximately 10 fold for every $61.5 \mathrm{mV}$ of membrane potential at $37^{\circ} \mathrm{C}$ leading to $100-500$ fold accumulation in average mitochondria [56], see Figure 2. 


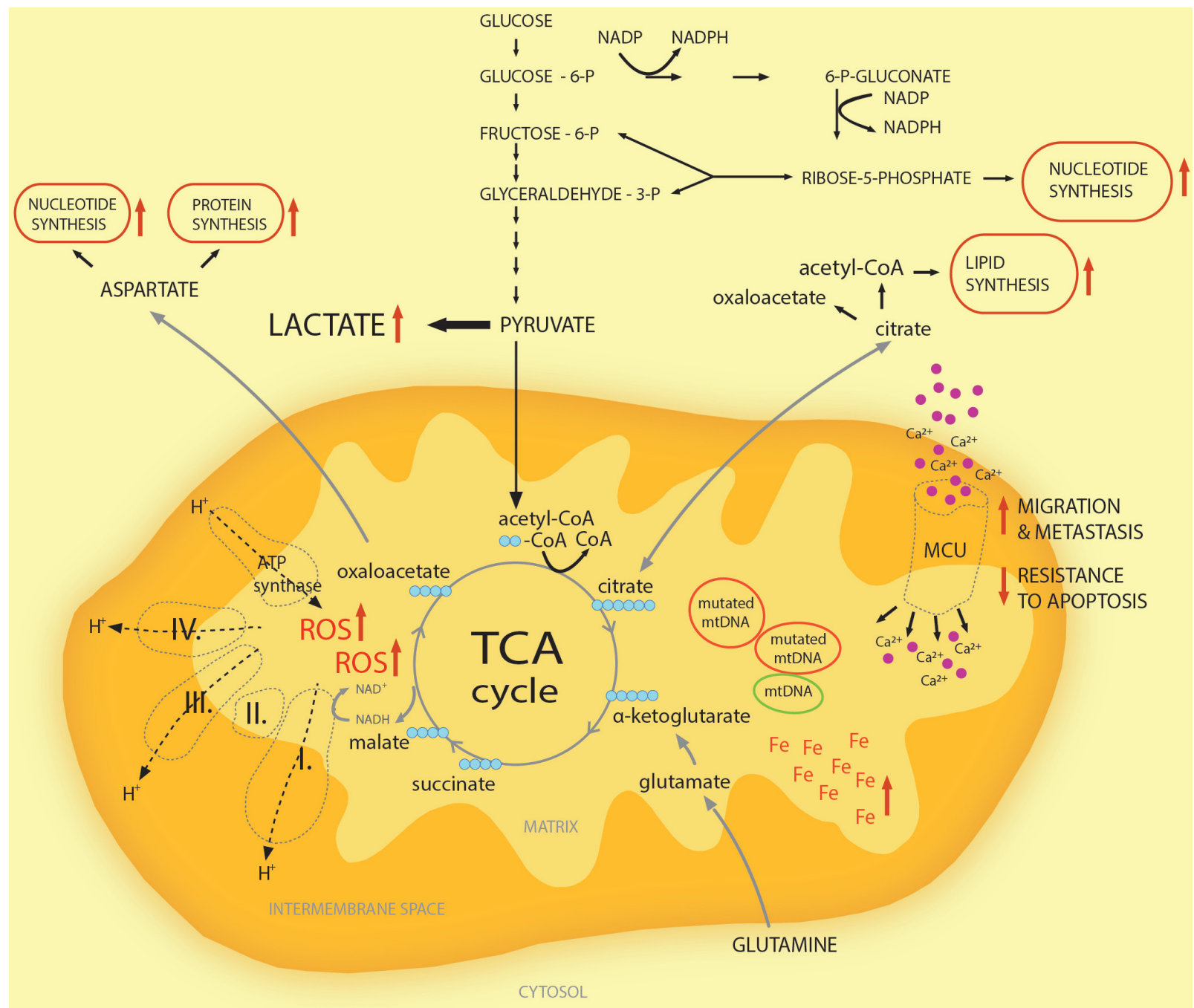

Figure 1. Mitochondrial function in cancer. A scheme of changes in mitochondrial functions in cancer cells. These include increased production of lactate, increased synthesis of lipids, amino acids and nucleotides, truncated function of the Krebs' cycle and the mitochondrial respiratory chain leading to increased production of ROS; a mutation in mtDNA and calcium homeostasis disbalance (increased/decreased levels) and increased levels of iron. For relevant references see the text.

Preferential accumulation of $\mathrm{TPP}^{+}$derivatives in mitochondria of cancer cells compared to normal cells. Since $\mathrm{TPP}^{+}$derivatives accumulate in functioning mitochondria of any cells, the obvious question is what mechanism may account for their relative selectivity for cancer cells. One of the explanations for this phenomenon is that cancer cells have both a higher plasma membrane potential and a higher mitochondrial membrane potential $[57,58]$. One study reported that the difference between control and carcinoma epithelial cell lines was approximately $60 \mathrm{mV}$ [59]. A similar increase in the mitochondrial membrane potential was shown in epithelial adenocarcinomas, particularly colon adenocarcinoma or tumorigenic bladder epithelial cell lines [57, 60, 61]. As in vitro studies have their own limitations, these results were also confirmed in vivo [62]. A study on breast carcinoma cells in situ produced similar results, however, a small percentage of patients showed instead a similarity with non-malignant epithelium [63]. This variability could be due to the heterogeneity of these tumors in vivo, where they are highly hormone dependent. Han et al. showed that $\mathrm{TPP}^{+}$ conjugated doxorubicin overcomes the resistance of breast cancer cells but exhibits a lack of selectivity, which may suggest that there is no difference in membrane potential compared to control cells [64]. Higher membrane potential was also not detected in leukemias, lymphomas, neuroblastomas or osteosarcomas [57].

It is reasonable to assume that the observed increase in the mitochondrial membrane potential in cancer cells results from structural or functional differences of some components of the organelle characteristic for this pathological process, such as disruptions in mitochondrial respiratory chain complexes, ATP synthase, adenine nucleotide 
translocator (ANT) or membrane lipid structure. Indeed, some cancer cell lines show alterations in various subunits of ATP synthase or cytochrome $c$ oxidase resulting in their lower activity $[65,66]$. This was also observed in a range of tumors [67-71]. This may have a negative impact on proton pumping and/or transport back into the matrix, which may result in changes in the mitochondrial membrane potential. There are, however, also reports suggesting the contrary - an increase not only in the expression of ATP synthase [72] but also its activity together with an increase of activity of the respiratory chain complexes [73] in breast cancer cells.

The discrepancies among the reports raise the question, whether previously shown disruptions in ATP synthase and cytochrome- $c$ oxidase are the main or only mechanisms for the observed higher membrane potential within most of the cancer cells. However, what other factors might be involved and influence the uptake of $\mathrm{TPP}^{+}$derivatives is currently not clear and the precise mechanism of the selectivity of mitochondrially targeted substances for cancer cells remains to be further elucidated.

The effect of the $\mathrm{TPP}^{+}$moiety itself on mitochondria in normal cells. While some studies of mitochondrially targeted compounds seem to assume that their effects are largely or entirely caused by the bioactive component, there is solid evidence that the $\mathrm{TPP}^{+}$moiety itself has significant effects on the mitochondrial function. $\mathrm{TPP}^{+}$derivatives may cause respiratory chain and Krebs cycle dysfunction, most likely via different mechanisms [74-76].

The first mechanism is most readily observed in $\mathrm{TPP}^{+}$ derivatives with a shorter alkyl chain, such as triphenylmethylphosphonium (TPMP). This molecule is less hydrophobic (compared to other $\mathrm{TPP}^{+}$derivatives substituted with longer alkyl chain), therefore a higher amount will be accumulated within the mitochondrial matrix, where it interacts with the 2-oxoglutarate dehydrogenase complex, a key enzyme of Krebs cycle, and causes its inhibition resulting in the inhibition of the mitochondrial respiration [76]. Interestingly, one study has shown that while TPMP decreases basal oxygen consumption rate, it causes a greater stimulation of respiration with FCCP after oligomycin [74].

The more hydrophobic derivatives tend preferentially to associate with the inner mitochondrial membrane; therefore their concentration within the mitochondrial matrix is lower compared to shorter derivatives. However, they directly interact with complexes of inner mitochondrial membrane, respiratory chain complexes included.

In the simple case of alkyl derivatives, their inhibitory effect on the respiratory chain complexes appears to correlate with the carbon chain length. Propyl or butyl derivatives show virtually no changes in any of the bioenergetic parameters compared to control, however, longer and more hydrophobic derivatives such as heptyl, decyl or dodecyl are far from inert. In $\mathrm{C} 2 \mathrm{C} 12$ cells, it has been shown that long chain alkyl derivatives increase proton leak and decrease maximal respiration, with the inhibition mostly centered on complex

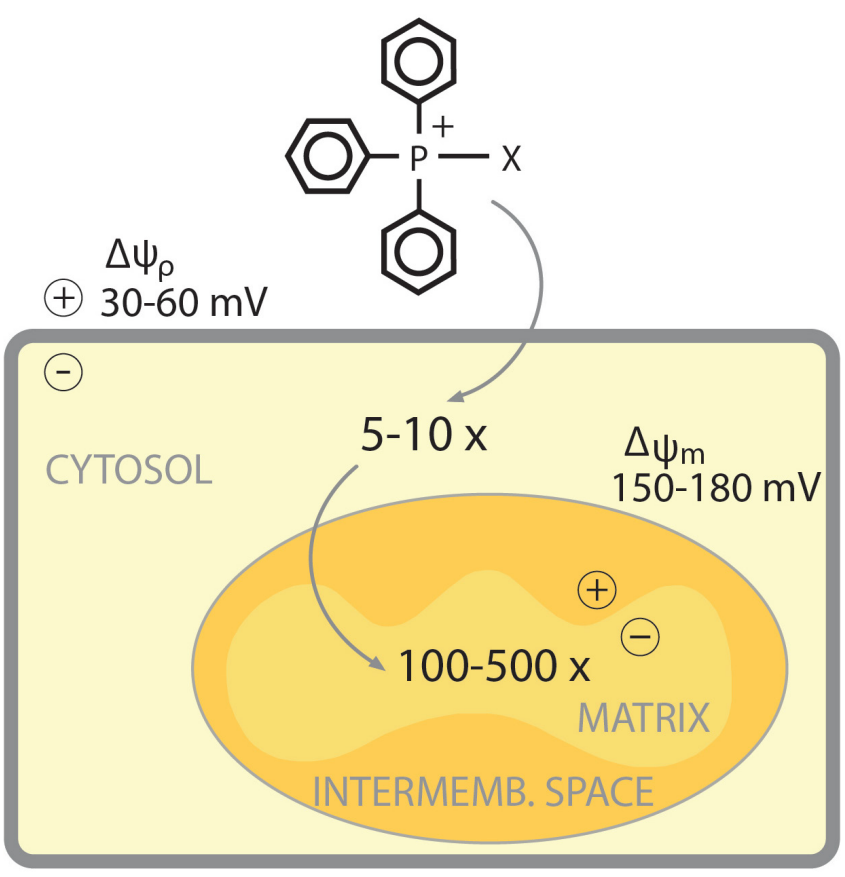

Figure 2. Uptake of $\mathrm{TPP}^{+}$derivatives by mitochondria. The uptake of the $\mathrm{TPP}^{+}$-conjugated compound $\mathrm{X}$ into the cytoplasm from the extracellular space is driven by the plasma membrane potential and its subsequent accumulation in mitochondria is driven by the mitochondrial membrane potential. Both processes are happening according to the Nernst equation. The plasma and mitochondrial membrane potentials $(\Delta \psi)$ are indicated. Scheme modified from Murphy [106].

I and complex III. The observed effect is proportional to the increase of the length of the alkyl chain and concentration [75]. When mouse kidney mesangial cells were treated with decyl-TPP ${ }^{+}$, a decrease in oxygen consumption rate was observed, however, interestingly this effect reverted after 20 minutes, and oligomycin did not cause a decrease in the oxygen consumption rate (OCR) and the addition of FCCP resulted in an inhibition, rather than stimulation of respiration [74]. Decyl and dodecyl TPP derivatives also cause the collapse of the mitochondrial membrane potential, likely due to direct disruption of the lipid bilayer structure. In all cases, different $\mathrm{TPP}^{+}$derivatives, regardless of the length of the alkyl chain and of the specific cell line used, cause an increase of the extracellular acidification rate (ECAR) suggesting a defect in OXPHOS [74-76].

$\mathrm{TPP}^{+}$derivatives also cause an inhibition of calcium efflux from mitochondria through a direct interaction with $\mathrm{Na}^{+}$/ $\mathrm{Ca}^{2+}$ exchanger [77, 78]. A toxic effect of $\mathrm{TPP}^{+}$derivatives was also demonstrated in vivo [79].

The effect of the $\mathrm{TPP}^{+}$moiety itself on mitochondria in cancer cells. The $\mathrm{TPP}^{+}$moiety is a common feature of many different bioactive compounds tested for anti-cancer effects. Some believe that the $\mathrm{TPP}^{+}$moiety itself might have anti-cancer effects; however, a detailed mechanism remains to be elucidated. As mentioned above, the main function 
of this moiety is to specifically target mitochondria leading to a higher accumulation of the molecule in the mitochondria, therefore potentiating the effect of bioactive compound [80], bypassing unwanted DNA repair mechanisms [81], decreasing the adverse effects [82] or preventing drug efflux mechanisms [64, 82]. Having anticancer drugs conjugated to the $\mathrm{TPP}^{+}$moiety increases their penetration into tumor mitochondria due to their often higher mitochondrial membrane potential (as discussed above).

These findings seem to be consistent in most of the reported studies, but there are also contrary findings. Cheng et al. reported that decyl-TPP ${ }^{+}$itself did not show any selectivity to pancreatic ductal adenocarcinoma cells compared to non-malignant cells. Interestingly, when decyl-TPP ${ }^{+}$was conjugated to metformin, there was a higher selectivity to cancer cells compared to normal cells, where the precise mechanism of this observed effect was not specified [83].

Some studies suggest that the moiety itself is mostly inert $[64,81,83,84]$, and the conjugation may lead to the inertness of the whole pro-drug preventing it from full activation [85]. On the contrary, other studies have suggested that $\mathrm{TPP}^{+}$itself can potentiate or modulate the cytotoxic effect. The length of the alkyl chain of $\mathrm{TPP}^{+}$derivatives has an impact on the effectiveness of the drug [83], as does the increase of the number of the $\mathrm{TPP}^{+}$moieties [85]. This finding is at odds with the report from Ross et al., who showed that bis- $\mathrm{TPP}^{+}$dications struggle to accumulate in mitochondria [86]. Doxorubicin itself induces apoptosis, however, when conjugated to $\mathrm{TPP}^{+}$ it has been shown to trigger necrosis [87].

This summary clearly shows that the effects of the TPP ${ }^{+}$ moiety with or without a conjugated bioactive compound require much more detailed research before a rational design of effective anticancer agents becomes possible.

\section{Mitochondrially targeted anticancer agents}

Bioactive compounds conjugated to $\mathrm{TPP}^{+}$so far appearing in the literature can be divided into four categories: 1) conventional cytotoxic drugs 2) natural substances 3 ) molecules originally used for the treatment of diseases other than cancer or 4) new $\mathrm{TPP}^{+}$derivatives.

Cytotoxic drugs. A range of commonly used cytotoxic agents such as cisplatin, doxorubicin, paclitaxel or tamoxifen has been conjugated to $\mathrm{TPP}^{+}$. Additionally, some of these derivatives have been further connected to different nanocarrier systems and tested for specific mitochondrial drug delivery [81, 82, 87].

The main target of cisplatin is nuclear DNA, where it functions by directly binding to purine bases leading to DNA damage. However, its resistance to DNA repair mechanisms and non-selectivity to cancer cells often complicates the treatment and leads to lower efficacy [88-90].

Studies have shown that cisplatin conjugated to $\mathrm{TPP}^{+}$ preferentially accumulates inside mitochondria, therefore

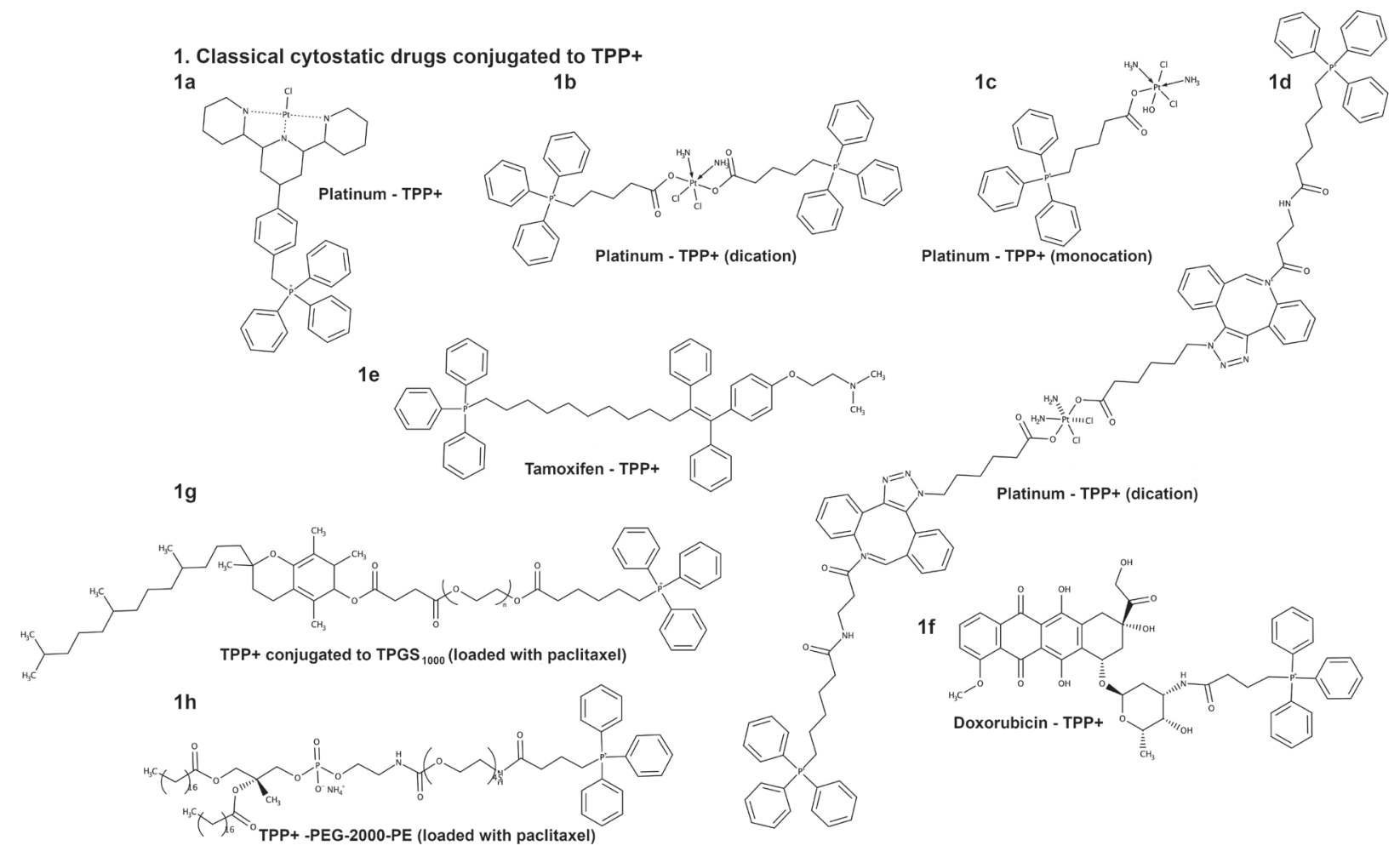

Figure 3. Chemical structures of $\mathrm{TPP}^{+}$-conjugated anticancer agents. Part 1. 
bypassing its nuclear DNA mechanisms. $\mathrm{TPP}^{+}$-cisplatin accumulated within mitochondria binds to mtDNA, inhibits mitochondrial respiration and the mitochondrial antioxidant enzyme thioredoxin reductase (TrxR), and causes cristae remodeling, resulting in enhanced cytotoxicity even in cisplatin-resistant cells. These compounds also showed lower toxicity towards normal cells. For chemical structures see Figure 3; 1a-d [81, 85, 91].

Tamoxifen conjugated to $\mathrm{TPP}^{+}$(MitoTAM, Figure 3; 1e) accumulates in mitochondria of breast cancer cells and tumors overexpressing Her2 oncogene and causes disruptions of supercomplexes, inhibition of complex I, dissipation of the membrane potential and an increase of ROS production. Additionally, it exhibited cytotoxicity against cancer cells both in vitro and in vivo without inducing senescence [92, 93].

Doxorubicin, when conjugated to $\mathrm{TPP}^{+}$(Figure 3; 1f), acts mainly through the disruption of mitochondrial metabolism rather than the classical, well-studied interaction with topoisomerase II in the nucleus. In an interesting twist to the conventional targeting method, attaching $\mathrm{TPP}^{+}$to a nanoparticle carrying doxorubicin induced severe and acute cytotoxicity in prostate carcinoma cells, which was mainly of a necrotic nature, compared to doxorubicin itself [87]. However, this is not in accordance with other reports showing increased cytotoxicity via apoptosis in melanocytes treated with $\mathrm{TPP}^{+}$-doxorubicin [64]. $\mathrm{TPP}^{+}$-doxorubicin combined with hyaluronic acid caused an increase in ROS production and cytotoxicity in breast cancer cells. This effect was also observed in tumor-bearing zebrafish where it significantly inhibited tumor growth and prolonged survival compared to unconjugated doxorubicin [82].

$\mathrm{TPP}^{+}$-conjugated nanocarriers loaded with paclitaxel (Figure 3; 1g, 1h) specifically targeted mitochondria in cancer cells, effectively killing the cells in vitro and inhibiting tumor growth in vivo in $4 \mathrm{~T} 1$ tumor-bearing mice. At the same time, no toxic side effects were observed in animals [94, 95].
2. Natural substances conjugated to TPP+

$2 a$

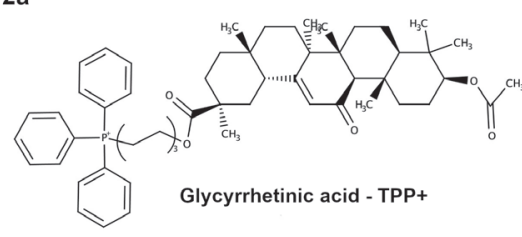

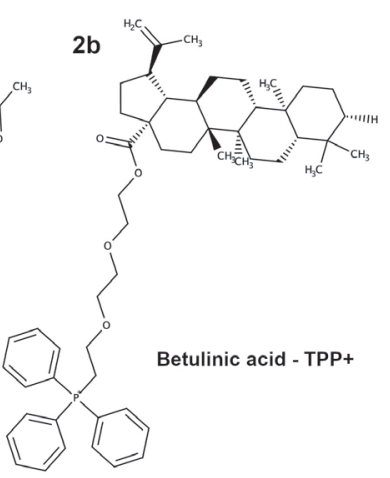

3. Conventional drugs with a new role in cancer conjugated to TPP+

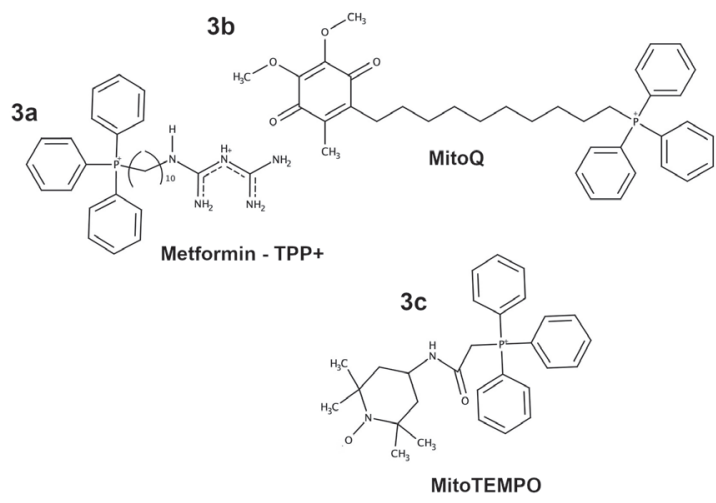

4. New TPP+ derivatives

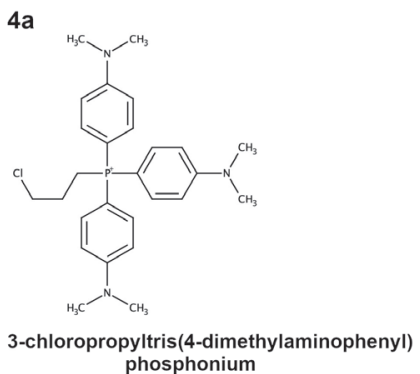

$4 \mathrm{e}$

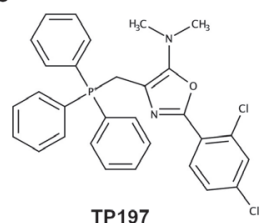

$4 b$

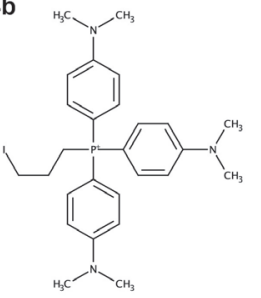

3-iodopropyltris(4-dimethylaminophenyl) phosphonium

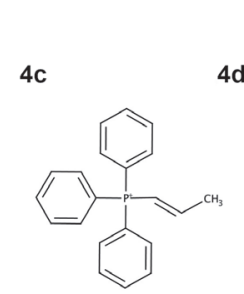

(E)-(prop-1-en-1-yl) - TPP+

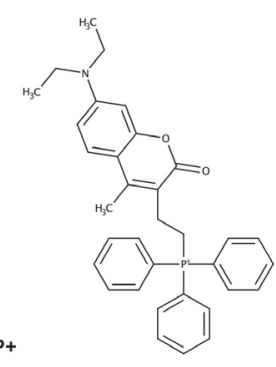

TP421
$4 \mathrm{~g}$

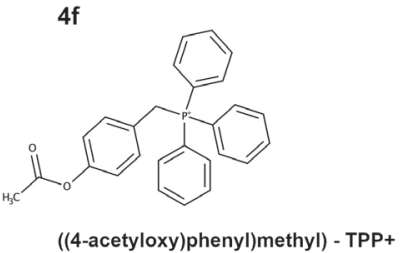

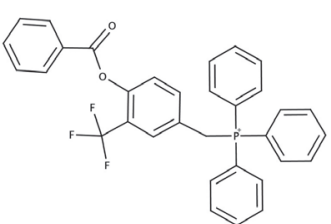

(3-trifluoromethyl-4-benzoyloxyphenyl)methyl) - TPP+

Figure 4. Chemical structures of $\mathrm{TPP}^{+}$-conjugated anticancer agents. Part 2. 
Natural substances. Glycyrrhetinic acid, a pentacyclic triterpenoid obtained from the plant Glycyrrhiza glabra, has been shown to have anti-tumor activity. However, its low bioavailability, poor aqueous solubility, and limited intracellular accumulation limit its usage. The conjugation of glycyrrhetinic acid to $\mathrm{TPP}^{+}$eliminates these obstacles. This compound (Figure 4; 2a) specifically targets mitochondria to induce cell cycle arrest, inhibits cancer cells proliferation and migration. Additionally, it causes the collapse of the mitochondrial membrane potential, increases the production of reactive oxygen species and activates pro-apoptotic proteins triggering apoptosis with some selectivity for cancer cells compared to normal cells [96].

Similar to glycyrrhetinic acid, betulinic acid is a highly hydrophobic compound and has poor blood solubility and therefore limited intracellular accumulation. However, when conjugated to $\mathrm{TPP}^{+}$its properties are markedly modified. It leads to increased bioavailability and higher cytotoxic activity against cancer cells, due to its preferential accumulation in mitochondria, where it suppresses mitochondrial respiration and induces the apoptotic cascade (Figure 4; 2b) [97].

Conventional drugs with a new role in cancer metformin and antioxidants. Metformin is a standard drug used to treat type 2 diabetes mellitus. There is overwhelming evidence that patients suffering from diabetes mellitus had a significantly increased risk for cancer, however, in patients treated with metformin this risk was decreased [98]. In another study, metformin showed inhibition of cell and tumor growth and an enhanced response to ionizing radiation in non-small cell lung cancer [99]. These effects of metformin were potentiated by its conjugation to $\mathrm{TPP}^{+}$, which led to increased bioavailability. Pancreatic cancer cells treated with $\mathrm{TPP}^{+}$-metformin (MitoMet, Figure 4; 3a) showed higher radiation sensitivity, increased activation of adenosine monophosphate kinase (AMPK) and a decrease of a redox responsive transcription factor FOXM1. Additionally, there was a significant decrease of oxygen consumption rate, inhibition of complex I activity and increased production of ROS with an inhibition of cell growth. Suppression of tumor growth upon treatment with MitoMet was confirmed also in vivo [83].

The mechanism of action of many anticancer drugs, including those mentioned above, is based on an increase of ROS above threshold levels either via disruptions of the respiratory chain or by other, so far not well-described mechanisms, often resulting in apoptosis. At the same time, a certain elevation of ROS in cancer cells compared to normal cells is crucial to causing their genetic instability [100], as well as promoting cell growth and proliferation [101]. Based on this, mitochondrial targeted antioxidants, such as MitoTEMPO or MitoQ (Figure 4; 3b, 3c), have been tested as potential anticancer drugs showing promising results [102].

New TPP $^{+}$derivatives. Not only different chemotherapeutic drugs conjugated to $\mathrm{TPP}^{+}$have been shown to have promising anticancer effects, but also other $\mathrm{TPP}^{+}$derivatives.
Tetraphenylphosphonium cation and other phosphonium cations selectively inhibited the growth of human pancreatic carcinoma-derived cells [103]. 3-chloropropyltris(4dimethylaminophenyl) phosphonium chloride (APPCL) and 3-iodopropyltris(4-dimethylaminophenyl) phosphonium iodide (APPI) showed promising anticancer effects, including cell lines and mouse models resistant to conventional drugs [104]. Their chemical structures are shown in Figure 4; $4 \mathrm{a}, 4 \mathrm{~b}$.

Another report showed that $\mathrm{TPP}^{+}$derivatives with (E)-(prop-1-en-1-yl), 2-(oxazol-4-ylmethyl) or 2-ethyl-4-(2oxo-2H-chromen-3-yl) (Figure 4, 4c-e) caused a decrease in the OCR, a concomitant increase of ROS, which altered redox sensitive cell signaling pathways resulting in an inhibition of growth factor-mediated signaling, promotion of cell cycle arrest and induction of apoptosis [105].

Esterified phenol derivatives conjugated with the $\mathrm{TPP}^{+}$ cation (Figure 4; $4 \mathrm{f}-\mathrm{g}$ ) showed a specific cytotoxic effect against some cancer cell lines, particularly lung cancer and osteosarcoma. The differences in cytotoxicity between various cell lines might correlate with their metabolic differences. PGC- $1 \alpha$, a regulator of mitochondrial biogenesis, is inactivated by these compounds in lung cancer cells, resulting in a reduction of mitochondrial mass and energy metabolism. The high accumulation of these compounds within mitochondria leads to a higher production of ROS, which results in apoptosis. Interestingly, the non-esterified versions failed to accumulate sufficiently in mitochondria [84].

\section{Conclusion}

Mitochondria have become an exciting new drug target for anticancer therapy. A wide range of bioactive molecules conjugated to $\mathrm{TPP}^{+}$, and indeed simple $\mathrm{TPP}^{+}$derivatives themselves, have shown promising anti-tumor activity despite the fact that the mechanisms of their actions remain unclear. In order to further the research into new, mitochondrially targeted anticancer agents and perhaps to bring about the promise of more cancer-selective, less damaging treatments, more attention needs to be brought to the molecular mechanisms of $\mathrm{TPP}^{+}$interactions inside cells and mitochondria, on their effects on energy metabolism and, crucially, on their unexpected and adverse effects.

From the review of literature, it is clear that the conjugation of a biologically active molecule often significantly alters its mechanism of action and its molecular targets, while at the same time conserving or enhancing its antiproliferative effects. While it is conceivable that there exist biologically inactive $\mathrm{TPP}^{+}$-conjugated compounds that do not appear in the literature due to the fact of their inefficacy (the wellknown negative result gap), the wide range of molecules that, after conjugation with triphenylphosphonium, exhibit cytotoxic effects suggests that the $\mathrm{TPP}^{+}$moiety is often more than just a targeting tool. There is a glaring lack of published studies of targeted molecules using unstable linkers, which 
would allow the release of the biologically active molecule from the targeting moiety. While this is likely mostly due to the inherent complications linked to their synthesis and stability in biological systems, only such molecules could provide us with a clearer understanding of the pharmacology of mitochondrial targeting and, furthermore, with a clearer path towards the development of safer and more efficacious treatments.

Acknowledgments: This work was supported by PROGRESQ36-METAB-GAP UK from Charles University. The authors would like to thank Valéria Gašparová for help with drawing the figures.

\section{References}

[1] WARBURG O, SEIGO M. Versuche an Überlebendem Carcinom-gewebe. Klin Wochenschr 1923; 2: 776-777. https:// doi.org/10.1007/BF01712130

[2] WARBURG OB, WIND F, NEGELEIN N. The metabolism of tumours in the body. J Gen Physiol 1927; 8: 519-530. https://doi.org/10.1085/jgp.8.6.519

[3] VANDER HEIDEN MG, CANTLEY LC, THOMPSON CB. Understanding the Warburg Effect: The Metabolic Requirements of Cell Proliferation. Science 2009; 324: 1029-1033. https://doi.org/10.1126/science.1160809

[4] ESTRELLA V, CHEN T, LLOYD M, WOJTKOWIAK J, CORNNELL $\mathrm{HH}$ et al. Acidity generated by the tumor microenvironment drives local invasion. Cancer Res 2013; 73: 1524-1535. https://doi.org/10.1158/0008-5472.CAN-122796

[5] BROOKS GA. Lactate shuttles in Nature. Biochem Soc Trans 2002; 30: 258-264.

[6] SONVEAUX P, VÉGRAN F, SCHROEDER T, WERGIN MC, VERRAX J et al. Targeting lactate-fueled respiration selectively kills hypoxic tumor cells in mice. J Clin Invest 2008; 118: 3930-3942. https://doi.org/10.1172/JCI36843

[7] ZU XL, GUPPY M. Cancer metabolism: facts, fantasy, and fiction. Biochem Biophys Res Commun 2004; 313: 459-465. https://doi.org/10.1016/j.bbrc.2003.11.136

[8] JOSE C, BELLANCE N, ROSSIGNOL R. Choosing between glycolysis and oxidative phosphorylation: A tumor's dilemma? Biochim Biophys Acta 2011; 1807: 552-561. https://doi. org/10.1016/j.bbabio.2010.10.012

[9] HATZIVASSILIOU G, ZHAO F, BAUER DE, ANDREADIS C, SHAW AN et al. ATP citrate lyase inhibition can suppress tumor cell growth. Cancer Cell 2005; 8: 311-321. https://doi. org/10.1016/j.ccr.2005.09.008

[10] DEBERARDINIS RJ, MANUCUSO A, DAIKHIN E, NISSIM I, YUDKOFF M et al. Beyond aerobic glycolysis: Transformed cells can engage in glutamine metabolism that exceeds the requirement for protein and nucleotide synthesis. Proc Natl Acad Sci U S A. 2007; 104: 19345-19350. https:// doi.org/10.1073/pnas.0709747104

[11] METALLO CM, GAMEIRO PA, BELL EL, MATTAINI KR, YANG J et al. Reductive glutamine metabolism by IDH1 mediates lipogenesis under hypoxia. Nature 2011; 481:380-384. https://doi.org/10.1038/nature10602
[12] BIRSOY K, WANG T, WALTER WC, FREINKMAN E, ABUREMAILEH M et al. An Essential Role of the Mitochondrial Electron Transport Chain in Cell Proliferation Is to Enable Aspartate Synthesis. Cell 2015; 162: 540-551. https://doi. org/10.1016/j.cell.2015.07.016

[13] OWUSU-ANSAH E, YAVARI A, MANDAL S, BANERJEE U. Distinct mitochondrial retrograde signals control the G1-S cell cycle checkpoint. Nat Genet 2008; 40: 356-361. https://doi.org/10.1038/ng.2007.50

[14] WEINBERG F, HAMANAKA R, WHEATON WW, JOSEPH J, LOPEZ $\mathrm{M}$ et al. Mitochondrial metabolism and ROS generation are essential for Kras-mediated tumorigenicity. Proc Natl Acad Sci U S A. 2010; 107: 8788-8793. https://doi. org/10.1073/pnas.1003428107

[15] LI T, HAN J, JIA L, HU X, CHEN L et al. PKM2 coordinates glycolysis with mitochondrial fusion and oxidative phosphorylation. Protein Cell 2019; 10: 583-594. https://doi. org/10.1007/s13238-019-0618-Z

[16] GAMMAGE PA, FREZZA C. Mitochondrial DNA : the overlooked oncogenome? BMC Biol 2019; 17: 53. https:// doi.org/10.1186/s12915-019-0668-y

[17] LOPEZ J, TAIT SWG. Mitochondrial apoptosis : killing cancer using the enemy within. Br J Cancer 2015; 112: 957-962. https://doi.org/10.1038/bjc.2015.85

[18] MARTINOU JC, YOULE RJ. Mitochondria in Apoptosis: Bcl-2 Family Members and Mitochondrial Dynamics. Dev Cell 2011; 21: 92-101. https://doi.org/10.1016/j.devcel.2011.06.017

[19] VILLUNGER A, MICHALAK EM, COULTAS L, MULLAUER F, BOCK G et al. p53- and Drug-Induced Apoptotic Responses Mediated by BH3-Only Proteins Puma and Noxa. Science 2003; 302: 1036-1038. https://doi.org/10.1126/science. 1090072

[20] PUTHALAKATH H, REILLY LAO, GUNN P, LEE L, KELLY PN et al. ER Stress Triggers Apoptosis by Activating BH3Only Protein Bim. Cell 2007; 129: 1337-1349.

[21] TAIT SWG, GREEN DR. Mitochondria and cell death : outer membrane permeabilization and beyond. Nat Rev Mol Cell Biol 2010; 11: 621-632. https://doi.org/10.1038/nrm2952

[22] MCDONNELL TJ, KORSMEYER SJ. Progression form hymphoid hyperplasia to high-grade malignant lymphoma in mice transgenic for the $t(14 ; 18)$. Nature 1991; 349: 254-256. https://doi.org/10.1038/349254a0

[23] DEGENHARDT K, CHEN G, LINDSTEN T, WHITE E. BAX and BAK mediate p53-independent suppression of tumorigenesis. Cancer Cell 2002; 2: 193-203. https://doi. org/10.1016/s1535-6108(02)00126-5

[24] RIZZUTO R, BERNARDI P, POZZAN T. Mitochondria as all-round players of the calcium game. J Physiol 2000; 529: 37-47. https://doi.org/10.1111/j.1469-7793.2000.00037.x

[25] VARANITA T, SORIANO ME, ROMANELLO V, ZAGLIA T, QUINTANA-CABRERA R et al. The Opal-dependent mitochondrial cristae remodeling pathway controls atrophic, apoptotic, and ischemic tissue damage. Cell Metab 2015; 21: 834-844. https://doi.org/10.1016/j.cmet.2015.05.007

[26] WAN B, LANOUE KF, CHEUNG JY, SCADUTO RC. Regulation of citric acid cycle by calcium. J Biol Chem 1989; 264: 13430-13439. 
[27] PRUDENT J, POPGEORGIEV N, GADET R, DEYGAS M, RIMOKH R et al. Mitochondrial Ca2+ uptake controls actin cytoskeleton dynamics during cell migration. Sci Rep 2016; 6: 36570 . https://doi.org/10.1038/srep36570

[28] CAMPELLO S, LACALLE RA, BETTELLA M, MAÑES S, SCORRANO L et al. Orchestration of lymphocyte chemotaxis by mitochondrial dynamics. J Exp Med 2006; 203: 2879-2886. https://doi.org/10.1084/jem.20061877

[29] STRITTMATTER L, SANCAK Y, PLOVANICH M, BELCHER-TIMME CA, GOLDBERGER O et al. Integrative genomics identifies $\mathrm{MCU}$ as an essential component of the mitochondrial calcium uniporter. Nature 2011; 476: 341-345. https://doi.org/10.1038/nature10234

[30] RAFFAELLO A, TEARDO E, RIZZUTO R, SZABÒ I, DE STEFANI D. A forty-kilodalton protein of the inner membrane is the mitochondrial calcium uniporter. Nature 2011; 476: 336-340. https://doi.org/10.1038/nature10230

[31] GIRGIS HS, BAO XR, MCCOMBS JE, MOOTHA VK, GOHIL VM et al. MICU1 encodes a mitochondrial EF hand protein required for Ca2+ uptake. Nature 2010; 467: 291296. https://doi.org/10.1038/nature09358

[32] SANCAK Y, MARKHARD AL, KITAMI T, KOVÁCS-BOGDÁN E, KAMER KJ et al. EMRE is an essential component of the mitochondrial calcium uniporter complex. Science 2013; 342: 1379-1382. https://doi.org/10.1126/science.1242993

[33] HALL DD, WU Y, DOMANN FE, SPITZ DR, ANDERSON ME. Mitochondrial Calcium Uniporter Activity Is Dispensable for MDA-MB-231 Breast Carcinoma Cell Survival. PLoS One 2014; 9: e96866. https://doi.org/10.1371/journal. pone.0096866

[34] MARCHI S, LUPINI L, PATERGNANI S, RIMESSI A, MISSIROLI $S$ et al. Downregulation of the mitochondrial calcium uniporter by cancer-related miR-25. Curr Biol 2013; 23: 58-63. https://doi.org/10.1016/j.cub.2012.11.026

[35] TOSATTO A, SOMMAGGIO R, KUMMEROW C, BENTHAM RB, BLACKER TS et al. The mitochondrial calcium uniporter regulates breast cancer progression via HIF-1 $\alpha$. EMBO Mol Med 2016; 8: 569-585. https://doi.org/10.15252/ emmm.201606255

[36] TANG S, WANG X, SHEN Q, YANG X, YU C et al. Mitochondrial $\mathrm{Ca} 2+$ uniporter is critical for store-operated Ca $2+$ entry-dependent breast cancer cell migration. Biochem Biophys Res Commun 2015; 458: 8-13. https://doi. org/10.1016/j.bbrc.2015.01.013

[37] KHIROYA H, MOORE JS, AHMAD N, KAY J, WOOLNOUGH K et al. IRP2 as a potential modulator of cell proliferation, apoptosis and prognosis in nonsmall cell lung cancer. Eur Respir J 2017; 49: 1602245. https://doi. org/10.1183/13993003.02245-2016

[38] KUANG Y, GUO W, LING J, XU D, LIAO Y et al. Iron-dependent CDK1 activity promotes lung carcinogenesis via activation of the GP130/STAT3 signaling pathway. Cell Death Dis 2019; 10: 12. https://doi.org/10.1038/s41419-018-1277-3

[39] BROOKES MJ, HUGHES S, TURNER FE, REYNOLDS G, SHARMA $\mathrm{N}$ et al. Modulation of iron transport proteins in human colorectal carcinogenesis. Gut 2006; 55: 1449-1460. https://doi.org/10.1136/gut.2006.094060
[40] MUTO Y, MOROISHI T, ICHIHARA K, NISHIYAMA M, SHIMIZU H et al. Disruption of FBXL5-mediated cellular iron homeostasis promotes liver carcinogenesis. J Exp Med 2019; 216: 950-965. https://doi.org/10.1084/jem.20180900

[41] BOULT J, ROBERTS K, BROOKES MJ, HUGHES S, BURY $\mathrm{JP}$ et al. Overexpression of cellular iron import proteins is associated with malignant progression of esophageal adenocarcinoma. Clin Cancer Res 2008; 14: 379-387. https://doi. org/10.1158/1078-0432.CCR-07-1054

[42] WARD DM, CLOONAN SM. Mitochondrial Iron in Human Health and Disease. Annu Rev Physiol 2019; 81: 453-482. https://doi.org/10.1146/annurev-physiol-020518-114742.

[43] LI C, ZHANG Y, CHENG X, YUAN H, ZHU S et al. PINK1 and PARK2 Suppress Pancreatic Tumorigenesis through Control of Mitochondrial Iron-Mediated Immunometabolism. Dev Cell 2018; 46: 441-455.e8. https://doi. org/10.1016/j.devcel.2018.07.012

[44] XUE X, BREDELL BX, ANDERSON ER, MARTIN A, MAYS $\mathrm{C}$ et al. Quantitative proteomics identifies STEAP4 as a critical regulator of mitochondrial dysfunction linking inflammation and colon cancer. Proc Natl Acad Sci U S A 2017; 114: E9608-E9617. https://doi.org/10.1073/pnas.1712946114

[45] KRÄMER SD, LOMBARDI D, PRIMORAC A, THOMAE AV, WUNDERLI-ALLENSPACH H. Lipid-Bilayer Permeation of Drug-Like Compounds. Chem Biodivers 2009; 6: 1900-1916. https://doi.org/10.1002/cbdv.200900122

[46] SZETO HH, SCHILLER PW. Novel therapies targeting inner mitochondrial membrane-from discovery to clinical development. Pharm Res 2011; 28: 2669-2679. https://doi. org/10.1007/s11095-011-0476-8

[47] HORTON KL, STEWART KM, FONSECA SB, GUO Q, KELLEY SO. Mitochondria-Penetrating Peptides. Chem Biol 2008; 15: 375-382. https://doi.org/10.1016/j.chembiol.2008.03.015

[48] FINK MP, MACIAS CA, XIAO J, TYURINA YY, DELUDE RL et al. Hemigramicidin-TEMPO conjugates: Novel mitochondria-targeted antioxidants. Crit Care Med 2007; 35: S461467. https://doi.org/10.1097/01.CCM.0000279192.96303.E7

[49] JOHNSON L V, WALSH ML, and CHEN LANB Localization of mitochondria in living cells with rhodamine 123. Proc Natl Acad Sci U S A 1980; 77: 990-994. https://doi. org/10.1073/pnas.77.2.990

[50] SMITH RAJ, HARTLEY RC, COCHEME HM, MURPHY MP. Mitochondrial pharmacology. Trends Pharmacol Sci 2012; 33: 341-352. https://doi.org/10.1016/j.tips.2012.03.010

[51] SMITH RAJ, ADLAM VJ, BLAIKIE FH, MANAS AB, PORTEOUS CM et al. Mitochondria-Targeted Antioxidants in the Treatment of Disease. Ann N Y Acad Sci 2008; 1147: 105-111. https://doi.org/10.1196/annals.1427.003

[52] ROSS MF, MURPHY MP. Cell-penetrating peptides are excluded from the mitochondrial matrix. Biochem Soc Trans 2004; 32: 1072-1074. https://doi.org/10.1042/BST0321072

[53] JIANG J, KURNIKOV I, BELIKOVA NA, XIAO J, ZHAO Q et al. Structural Requirements for Optimized Delivery, Inhibition of Oxidative Stress, and Antiapoptotic Activity of Targeted Nitroxides. J Pharmacol Exp Ther 2007; 320: 10501060. https://doi.org/10.1124/jpet.106.114769 
[54] ZIELONKA J, JOSEPH J, SIKORA A, HARDY M, OUARI O et al. Mitochondria-Targeted Triphenylphosphonium-Based Compounds: Syntheses, Mechanisms of Action, and Therapeutic and Diagnostic Applications. Chem Rev 2017; 117: 10043-10120. https://doi.org/10.1021/acs.chemrev.7b00042

[55] ROSS MF, KELSO GF, BLAIKIE FH, JAMES AM, COCHEMÉ HM et al. Liphophilic Triphenylphosphonium Cations as Tools in Mitochondrial Bioenergetics and Free Radical Biology. Biochemistry (Mosc) 2005; 70: 222-230. https://doi. org/10.1007/s10541-005-0104-5

[56] MURPHY MP. Targeting lipophilic cations to mitochondria. Biochim Biophys Acta 2008; 1777: 1028-1031. https://doi. org/10.1016/j.bbabio.2008.03.029

[57] NADAKAVUKAREN JJ, BERNAL SD, NADAKAVUKAREN KK, SHEPHERD EL, CHEN LB et al. Unusual retention of rhodamine 123 by mitochondria in muscle and carcinoma cells. Proc Natl Acad Sci U S A 1982; 79: 5292-5296. https:// doi.org/10.1073/pnas.79.17.5292

[58] DAVIS S, WEISSP J, WONGLI JR, LAMPIDIS TJ, CEHN LB. Mitochondrial and Plasma Membrane Potentials Cause Unusual Accumulation and Retention of Rhodamine 123 by Human Breast. J Biol Chem 1985; 260: 13844-13850.

[59] MODICA-NAPOLITANO JS, APRILLE JR. Basis for the Selective Cytotoxicity of Rhodamine 123. Cancer Res 1987; 47: 4361-4365

[60] LAMPIDIS TJ, BERNAL SD, SUMMERHAYES IC, CHEN LB. Selective Toxicity of Rhodamine 123 in Carcinoma Cells in Vitro. Cancer Res 1983; 43: 716-720.

[61] BERNAL SD, LAMPIDIS TJ, SUMMERHAYES IC, CHEN LB. Rhodamine-123 selectively reduces clonal growth of carcinoma cells in vitro. Science 1982; 218: 1117-1119. https:// doi.org/10.1126/science.7146897

[62] BERNAL SD, LAMPIDIS TJ, MCISAAC RM, CHEN LB. Anticarcinoma activity in vivo of Rhodamine 123, a Mitochondrial-Specific Dye. Science 1983; 222: 169-172. https:// doi.org/10.1126/science.6623064

[63] DAIRKEE SH, HACKETT AJ. Differential retention of rhodamine 123 by breast carcinoma and normal human mammary tissue. Breast Cancer Res Treat 1991; 18: 57-61. https:// doi.org/10.1007/bf01975444

[64] HAN M, VAKILI MR, ABYANEH HS, MOLAVI O, LAI R et al. Mitochondrial Delivery of Doxorubicin via Triphenylphosphine Modification for Overcoming Drug Resistance in MDA-MB-435/DOX Cells. Mol Pharm 2014; 11: 2640-2649. https://doi.org/10.1021/mp500038g

[65] MODICA-NAPOLITANO JS, APRILLE JR. Delocalized lipophilic cations selectively target the mitochondria of carcinoma cells. Adv Drug Deliv Rev 2001; 49: 63-70. https://doi. org/10.1016/s0169-409x(01)00125-9

[66] CAPUANO F, GUERRIERI F, PAPA S. Oxidative phosphorylation enzymes in normal and neoplastic cell growth. J Bioenerg Biomembr 1997; 29: 379-384.

[67] CHEN J, KÄHNE T, RÖCKEN C, GÖTZE T, YU J et al. Proteome analysis of gastric cancer metastasis by two-dimensional gel electrophoresis and matrix assisted laser desorption/lonization-mass spectrometry for identification of metastasis-related proteins. J Proteome Res 2004; 3: 10091016. https://doi.org/10.1021/pr0499161
[68] ISIDORO A, MARTÍNEZ M, FERNÁNDEZ PL, ORTEGA Á, SANTAMARÍA G et al. Alteration of the bioenergetic phenotype of mitochondria is a hallmark of breast, gastric, lung and oesophageal cancer. Biochem J 2004; 378: 17-20. https://doi.org/10.1042/BJ20031541

[69] CUEZVA JM, CHEN G, ALONSO AM, ISIDORO A, MISEK DE et al. The bioenergetic signature of lung adenocarcinomas is a molecular marker of cancer diagnosis and prognosis. Carcinogenesis 2004; 25: 1157-1163. https://doi. org/10.1093/carcin/bgh113

[70] HE QY, CHEN J, KUNG HF, PO-WING YUEN A, CHIU JF. Identification of tumor-associated proteins in oral tongue squamous cell carcinoma by proteomics. Proteomics 2004; 4 : 271-278. https://doi.org/10.1002/pmic.200300550

[71] SUN AS, CEDERBAUM AI. Oxidoreductase Activities in Normal Rat Liver, Tumor-bearing Rat Liver, and Hepatoma HC-252. Cancer Res 1980; 40: 4677-4681.

[72] ISIDORO A, CASADO E, REDONDO A, ACEBO P, ESPINOSA E et al. Breast carcinomas fulfill the Warburg hypothesis and provide metabolic markers of cancer prognosis. Carcinogenesis 2005; 26: 2095-2104. https://doi.org/10.1093/ carcin/bgil 188

[73] KAAMBRE T, CHEKULAYEV V, SHEVCHUK I, KARUVARIKMAA M, TIMOHHINA $\mathrm{N}$ et al. Metabolic Control Analysis of cellular respiration in situ in intraoperational samples of human breast cancer. J Bioenerg Biomembr 2012; 44: 539-558. https://doi.org/10.1007/s10863-012-9457-9

[74] REILY C, MITCHELL T, CHACKO BK, BENAVIDES GA, MURPHY MP et al. Mitochondrially targeted compounds and their impact on cellular bioenergetics. Redox Biol 2013; 1: 86-93. https://doi.org/10.1016/j.redox.2012.11.009

[75] TRNKA J, ELKALAF M, ANDĚL M. Lipophilic triphenylphosphonium cations inhibit mitochondrial electron transport chain and induce mitochondrial proton leak. PLoS One 2015; 10: e0121837. https://doi.org/10.1371/journal. pone. 0121837

[76] ELKALAF M, TUMA P, WEISZENSTEIN M, POLÁK J, TRNKA J. Mitochondrial Methyltriphenylphosphonium (TPMP) Inhibits the Krebs Cycle Enzyme 2- Oxoglutarate Dehydrogenase. PLoS One 2016; 11: e0161413. https://doi. org/10.1371/journal.pone.0161413

[77] KARADJOV JS, KUDZINA LY, ZINCHENKO VP. TPP+ inhibits $\mathrm{Na}+$ - stimulated $\mathrm{Ca} 2+$ efflux from brain mitochondria. Cell Calcium 1986; 7: 115-119. https://doi. org/10.1016/0143-4160(86)90014-x

[78] LEOA S, SZABADKAIA G, RIZZUTO R. The Mitochondrial Antioxidants MitoE2 and MitoQ10 Increase Mitochondrial Ca2+ Load upon Cell Stimulation by Inhibiting Ca2+ Efflux from the Organelle. Ann N Y Acad Sci 2008; 1147: 264-274. https://doi.org/10.1196/annals.1427.019.

[79] POWELL RD, GOODENOW DA, CHRISTMAS BA, MCKILLOP IH, EVANS SL. Effect of systemic triphenylphosphonium on organ function and oxidative stress. Am Surg 2018; 84: 36-42.

[80] HUANG YC, KUO CL, LU KW, LIN JJ, YANG JL et al. $18 a-$ Glycyrrhetinic acid induces apoptosis of HL-60 human leukemia cells through caspases- and mitochondria-dependent signaling pathways. Molecules 2016; 21: E530. https:// doi.org/10.3390/molecules21050530 
[81] MARRACHE S, PATHAK RK, DHAR S. Detouring of cisplatin to access mitochondrial genome for overcoming resistance. Proc Natl Acad Sci U S A 2014; 111: 10444-10449. https://doi.org/10.1073/pnas.1405244111

[82] LIU H, GUO N, GUO W, HUANG-FU M, VAKILI MR et al. Delivery of mitochondriotropic doxorubicin derivatives using self-assembling hyaluronic acid nanocarriers in doxorubicin-resistant breast cancer. Acta Pharmacol Sin 2018; 39: 1681-1692. https://doi.org/10.1038/aps.2018.9

[83] CHENG G, ZIELONKA J, OUARI O, LOPEZ M, MCALLISTER D et al. Mitochondria-targeted analogs of metformin exhibit enhanced antiproliferative and radiosensitizing effects in pancreatic cancer cells. Cancer Res 2016; 76: 39043915. https://doi.org/10.1158/0008-5472.CAN-15-2534

[84] GAZZANO E, LAZZARATO L, ROLANDO B, KOPECKA J, STEFANO G et al. Mitochondrial Delivery of Phenol Substructure Triggers Mitochondrial Depolarization and Apoptosis of Cancer Cells. Front Pharmacol 2018; 9: 580. https:// doi.org/10.3389/fphar.2018.00580

[85] JIN S, HAO Y, ZHU Z, MUHAMMAD N, ZHANG Z et al. Impact of Mitochondrion-Targeting Group on the Reactivity and Cytostatic Pathway of Platinum(IV) Complexes. Inorg Chem. 2018 Sep 4; 57: 11135-11145. https://doi.org/10.1021/ acs.inorgchem. $8 \mathrm{~b} 01707$

[86] ROSS MF, DA ROS T, BLAIKIE FH, PRIME TA, PORTEOUS CM et al. of lipophilic dications by mitochondria and cells. Biochem J 2006; 400: 199-208. https://doi.org/10.1042/ BJ20060919

[87] THEODOSSIOU TA, SIDERATOU Z, KATSAROU ME, TSIOURVAS D. Mitochondrial delivery of doxorubicin by triphenylphosphonium- functionalized hyperbranched nanocarriers resultsinrapidandseverecytotoxicity.Pharm Res2013; 30: 2832-2842. https://doi.org/10.1007/s11095-013-1111-7

[88] SIDDIK ZH. Cisplatin: Mode of cytotoxic action and molecular basis of resistance. Oncogene 2003; 22: 7265-7279. https://doi.org/10.1038/sj.onc.1206933

[89] KELLAND L. The resurgence of platinum-based cancer chemotherapy. Nat Rev Cancer 2007; 7: 573-584. https://doi. org/10.1038/nrc2167

[90] AHMADI R, URIG S, HARTMANN M, HELMKE BM, KONCAREVIC $S$ et al. Antiglioma activity of 2,2':6','-terpy ridineplatinum(II) complexes in a rat model - Effects on cellular redox metabolism. Free Radic Biol Med 2006; 40: 763778. https://doi.org/10.1016/j.freeradbiomed.2005.09.031

[91] ZHU C, GUO Y, GUO Z, ZHOU W, WANG K et al. Restraining Cancer Cells by Dual-Metabolic Inhibitions with a Mitochondrion-Targeted Platinum(II) Complex. Angew Chem Int Ed Engl 2019; 58: 4638-4643. https://doi.org/10.1002/ anie. 201900387

[92] HUBACKOVA S, DAVIDOVA E, ROHLENOVA K, STURSA J, WERNER L et al. Selective elimination of senescent cells by mitochondrial targeting is regulated by ANT2. Cell Death Differ 2019; 26: 276-290. https://doi.org/10.1038/ s41418-018-0118-3

[93] ROHLENOVA K, SACHAPHIBULKIJ K, STURSA J, BEZAWORK-GELETA A, BLECHA J et al. Selective Disruption of Respiratory Supercomplexes as a New Strategy to Suppress Her2 high Breast Cancer. Antioxid Redox Signal 2017; 26: 84-103. https://doi.org/10.1089/ars.2016.6677
[94] BISWAS S, DODWADKAR NS, DESHPANDE PP, TORCHILIN VP. Liposomes loaded with paclitaxel and modified with novel triphenylphosphonium-PEG-PE conjugate possess low toxicity, target mitochondria and demonstrate enhanced antitumor effects in vitro and in vivo. J Control Release 2012; 159: 393-402. https://doi.org/10.1016/j.jconrel.2012.01.009

[95] ZHOU J, ZHAO WY, MA X, JU RJ, LI XY et al. The anticancer efficacy of paclitaxel liposomes modified with mitochondrial targeting conjugate in resistant lung cancer. Biomaterials 2013; 34: 3626-3638. https://doi.org/10.1016/j. biomaterials.2013.01.078

[96] JIN L, DAI L, JI M, WANG H. Mitochondria-targeted triphenylphosphonium conjugated glycyrrhetinic acid derivatives as potent anticancer drugs. Biomaterials 2013; 34: 36263638. https://doi.org/10.1016/j.biomaterials.2013.01.078

[97] NEDOPEKINA DA, GUBAIDULLIN RR, ODINOKOV VN, MAXIMCHIK PV, ZHIVOTOVSKY B et al. Mitochondria-targeted betulinic and ursolic acid derivatives: Synthesis and anticancer activity. Medchemcomm 2017; 8: 1934-1945. https://doi.org/10.1039/c7md00248c

[98] LEE MS, HSU CC, WAHLQVIST ML, TSAI HN, CHANG $\mathrm{YH}$ et al. Type 2 diabetes increases and metformin reduces total, colorectal, liver and pancreatic cancer incidences in Taiwanese: A representative population prospective cohort study of 800,000 individuals. BMC Cancer 2011; 11: 20. https://doi.org/10.1186/1471-2407-11-20

[99] STOROZHUK Y, HOPMANS SN, SANLI T, BARRON C, TSIANI E et al. Metformin inhibits growth and enhances radiation response of non-small cell lung cancer (NSCLC) through ATM and AMPK. Br J Cancer 2013; 108: 20212032. https://doi.org/10.1038/bjc.2013.187

[100] RADISKY DC, LEVY DD, LITTLEPAGE LE, LIU H, NELSON CM et al. Raclb and reactive oxygen species mediate MMP-3-induced EMT and genomic instability. Nature 2005; 436: 123-127. https://doi.org/10.1038/nature03688

[101] HU Y, ROSEN DG, ZHOU Y, FENG L, YANG G et al. Mitochondrial Manganese-Superoxide Dismutase Expression in Ovarian Cancer. J Biol Chem 2005; 280: 39485-39492. https://doi.org/10.1074/jbc.M503296200

[102] PORPORATO PE, PAYEN VL, PÉREZ-ESCUREDO J, DE SAEDELEER CJ, DANHIER P et al. A mitochondrial switch promotes tumor metastasis. Cell Rep 2014; 8: 754-766. https://doi.org/10.1016/j.celrep.2014.06.043

[103] RIDEOUT D, CALOGEROPOULOU T, JAWORSKI J, DAGNINO RJ, MCCARTHY M. Phosphonium salts exhibiting selective anti-carcinoma activity in vitro. Anticancer Drug Des 1989; 4: 265-280.

[104] MANETTA A, GAMBOA G, NASSERI A, PODNOS YD, EMMA D et al. Novel phosphonium salts display in vitro and in vivo cytotoxic activity against human ovarian cancer cell lines. Gynecol Oncol 1996; 60: 203-312. https://doi. org/10.1006/gyno.1996.0026

[105] MILLARD M, PATHANIA D, SHABAIK Y, TAHERI L, DENG J et al. Preclinical evaluation of novel triphenylphosphonium salts with broad-spectrum activity. PLoS One 2010; 5: e13131. https://doi.org/10.1371/journal.pone.0013131

[106] MURPHY MP. Understanding and preventing mitochondrial oxidative damage. Biochem Soc Trans 2016; 44: 1219 1226. https://doi.org/10.1042/BST20160108 